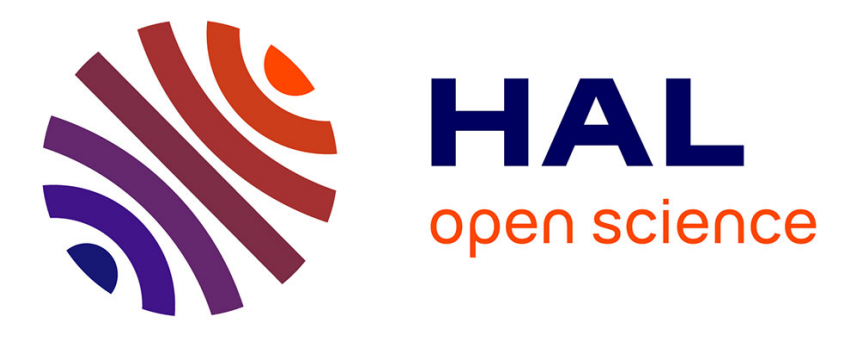

\title{
Auto-adaptive fault tolerant control of a seven-phase drive
}

\author{
Xavier Kestelyn, Yvan Crevits, Eric Semail
}

\section{To cite this version:}

Xavier Kestelyn, Yvan Crevits, Eric Semail. Auto-adaptive fault tolerant control of a seven-phase drive. 2010 IEEE International Symposium on Industrial Electronics (ISIE), Jul 2010, Italy. pp.21352140, 10.1109/ISIE.2010.5637784 . hal-00785584

\section{HAL Id: hal-00785584 https://hal.science/hal-00785584}

Submitted on 6 Feb 2013

HAL is a multi-disciplinary open access archive for the deposit and dissemination of scientific research documents, whether they are published or not. The documents may come from teaching and research institutions in France or abroad, or from public or private research centers.
L'archive ouverte pluridisciplinaire HAL, est destinée au dépôt et à la diffusion de documents scientifiques de niveau recherche, publiés ou non, émanant des établissements d'enseignement et de recherche français ou étrangers, des laboratoires publics ou privés. 


\title{
Auto-Adaptive Fault Tolerant Control of a Seven-phase Drive
}

\author{
Xavier KESTELYN, Yvan CREVITS and Eric SEMAIL \\ Arts et Métiers ParisTech L2EP. Bd Louis XIV 59046 Lille - France \\ Xavier.Kestelyn@ensam.eu
}

\begin{abstract}
This paper proposes an auto-adaptive current control that makes possible to reduce torque ripples of multi-phase machines in open-circuited phase conditions. Contrary to existing methods, current references are not recomputed and the control scheme used in normal mode is auto-adapted in order to run the machine with open-circuited phases. The number of degrees of freedom of the control scheme is adapted to the number of degrees of freedom of the drive and current controllers are auto-adaptive in order to reject the induced speed-dependent harmonic voltage disturbances that appear in fault-mode. Experimental results are presented to show the effectiveness of the proposed method.
\end{abstract}

\section{INTRODUCTION}

Many applications require fault-tolerant drives in order to ensure continuing security or productivity. Among existing solutions, multi-phase drives offer, due to their inherent additional degrees of freedom, an attractive alternative [1]. For example, a star-coupled n-phase machine can run with up to (n3 ) phases in fault-condition with no additional devices.

If many types of faults can occur, open-circuit faults are the most commonly found. In that case, currents in the healthy phases must be modified in order to reduce the impact of the fault on the torque quality. Several post-fault strategies may be applied. In most of the cases the objective is to keep a constant torque even with open-circuited phases. The two main limiting factors are then the thermal state of the machine, which is directly related to the level of Joule losses, and the maximum current per leg inverter, which is related to the peak machine current.

Two major sets of methods can be distinguished.

In the first method set [2]-[7], new current references are calculated off line (on line in [2]), considering different fault mode cases, in order to maintain a constant torque. Although these methods seem simple and direct, several drawbacks have to be highlighted. First, a new set of current references has to be computed and stored in tables for each case of fault-mode. For machines with a high number of phases, it leads to a high number of combinations and thereby to large capacity storage systems. Finally, the varying current waveforms impose the use of large bandwidth controllers such as hysteresis controllers, which are prohibited for high power systems.

In the second method set [8], for each case of fault-mode, a new transformation is calculated in order to obtain new $d q$ rotating reference frames. Although current references are kept constant whatever the functioning mode, a large number of transformations has to be stored in memory. Moreover, in order to be able to switch without discontinuity between several models, it is necessary to take care of the initialization of the new state variables when a fault occurs.

This paper proposes an auto-adaptive current control that makes possible to reduce torque ripples in open-circuited phase mode. Under the condition that the drive is specially design for fault-tolerant operations, this method makes possible to control the drive in normal as in open-circuited phase mode without calculating new current references or new references frames.

The basics of the method consist in adapting the number of degrees of freedom of the control scheme to the number of degrees of freedom of the drive. The quality of the torque waveform depends then directly on the current controller performances.

Section II presents the seven-phase drive which has been specifically designed for fault-tolerant applications. A unique model of the drive whatever the functioning mode is presented. Finally, the source of induced speed-dependent voltage harmonic perturbations in open-circuited phase condition is exhibited.

Section III details how the control scheme is adapted in order to keep a constant torque in fault-mode. Based on the harmonic content of the induced perturbations in fault-mode, the current controller design and tuning are presented.

Finally, section IV shows experimental results in order to prove the effectiveness of the proposed method.

\section{Unique Modelling Of a Multi-Phase Drive IN NORMAL AND OPEN-CIRCUITED PHASE CONDITIONS}

A. Unique modelling of the drive viable in normal mode as in opencircuited phase mode

The proposed drive is a star-coupled six-pole seven-phase NN TORUS machine with two external rotors which has been specially designed for fault-condition operations [9] (see Fig.1). The machine stator, with Gramme-ring windings, is soft magnetic composite made with 42 slots. The rotor permanent magnets have a specific shape in order to suppress the fifth harmonic of back electromotive forces.

To model open-circuited phases with keeping the same model for the machine, an additional variable resistor is added in series with the machine phases. This way of modelling 
makes possible to keep a unique model of the drive whatever the functioning mode (normal or open-circuited phases [10].

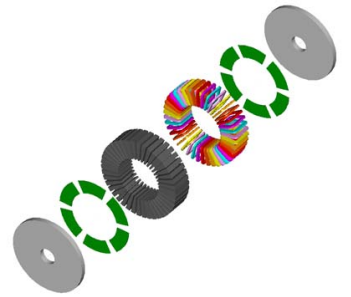

Fig. 1 Exploded view of the considered axial flux seven-phase machine.

Under classical assumptions and according to [10], the unique model of a seven-phase drive can be described by equations (1), (2) and (3):

$$
\begin{aligned}
& \vec{v}=\Re_{c}(\vec{i})+R \vec{i}+\Lambda\left(\frac{d \vec{i}}{d t}\right)+\vec{e} \\
& \operatorname{mat}\left(\Re_{c}, A B C\right)=\left(\begin{array}{cccc}
R_{c A} & 0 & \cdots & 0 \\
0 & R_{c B} & 0 & \vdots \\
\vdots & & \ddots & 0 \\
0 & \ldots & 0 & R_{c G}
\end{array}\right) \\
& T . \Omega=\vec{e} \cdot \vec{i}
\end{aligned}
$$

with:

- $\vec{v}, \vec{i}$ and $\vec{e}$ the seven-dimensional stator voltage, current and EMF vectors respectively.

- $\quad \Re_{c}$ a linear relation described by a 7-by-7 diagonal connexion resistance matrix. $R_{c k}=0$ if phase $k$ is connected to the supply or $R_{c k} \rightarrow \infty$ if phase $k$ is open-circuited.
- $R$, stator resistance and $\Lambda$, a linear relation described by a 7-by-7 stator inductance matrix.

- $T$, electromagnetic torque and $\Omega$, mechanical speed.

\section{B. Torque control structure}

The machine is controlled using a multi-reference frame approach [11][12]. Each 7-dimensional vector is split in three 2dimensional vectors (one dimension is ignored due to the starcoupling). Each 2-dimensional vector belongs to a twodimensional eigenspace of the initial 7-dimensional space. Since all eigenspaces are orthogonal, the initial 7-phase starcoupled machine can be considered as equivalent to a set of three fictitious two-phase machines (called M1, M2 and M3). These fictitious machines are magnetically independent and mechanically coupled on the same mechanical shaft.

Two-dimensional vector coordinates of each fictitious machine are obtained with a Concordia-type orthonormal transformation [12]. Variables belonging to a fictitious machine are called $\alpha \beta$ components.

Finally, since the considered machine in this paper has been specifically designed for fault operation, back-electromotive forces are mainly composed of harmonic one and three. The electromotive force of $M 2$ machine is ideally equal to zero. In order to have constant current references in steady state, a rotation operator is applied on $\alpha \beta$ components of machines $M 1$ and $M 3$. The overall control is then achieved in multiple $(d q)$ rotating reference frames.

Fig. 2 shows the structure of the chosen torque control where the torque references are generated in order to reduce the global Joule losses in normal mode.

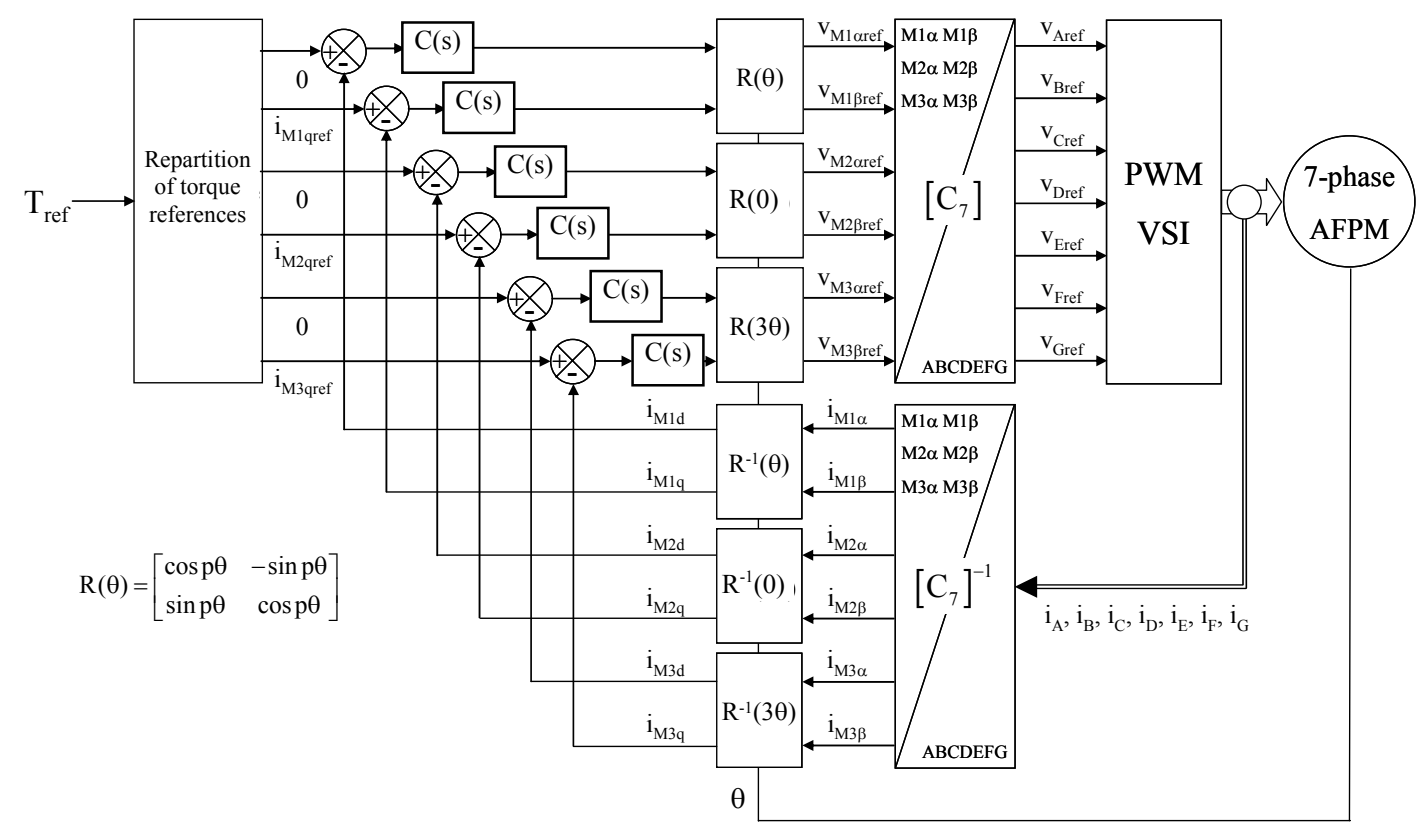

Fig. 2. Structure of the torque control 


\section{Analysis of the connection resistance matrix in $(\alpha \beta)$ and $(d q)$} reference frames

In order to evaluate the effects of open-circuited phases over $\alpha \beta$ components, the connection resistance matrix is expressed in $(\alpha \beta)$ reference frames by (4) with [C7] expressed by (5).

$$
\begin{aligned}
& \operatorname{mat}\left(\mathfrak{R}_{c}, \alpha \beta\right)=\left[C_{7}\right]^{-1} \operatorname{mat}\left(\mathfrak{R}_{c}, A B C\right)\left[C_{7}\right] \\
& {\left[C_{7}\right]=\sqrt{\frac{2}{7}}\left[\begin{array}{ccccccc}
1 & 0 & 1 & 0 & 1 & 0 & \frac{1}{\sqrt{2}} \\
\cos \frac{2 \pi}{7} & \sin \frac{2 \pi}{7} & \cos \frac{4 \pi}{7} & \sin \frac{4 \pi}{7} & \cos \frac{6 \pi}{7} & \sin \frac{6 \pi}{7} & \frac{1}{\sqrt{2}} \\
\cos \frac{4 \pi}{7} & \sin \frac{4 \pi}{7} & \cos \frac{8 \pi}{7} & \sin \frac{8 \pi}{7} & \cos \frac{12 \pi}{7} & \sin \frac{12 \pi}{7} & \frac{1}{\sqrt{2}} \\
\cos \frac{6 \pi}{7} & \sin \frac{6 \pi}{7} & \cos \frac{12 \pi}{7} & \sin \frac{12 \pi}{7} & \cos \frac{18 \pi}{7} & \sin \frac{18 \pi}{7} & \frac{1}{\sqrt{2}} \\
\cos \frac{8 \pi}{7} & \sin \frac{8 \pi}{7} & \cos \frac{16 \pi}{7} & \sin \frac{16 \pi}{7} & \cos \frac{24 \pi}{7} \sin \frac{24 \pi}{7} & \frac{1}{\sqrt{2}} \\
\cos \frac{10 \pi}{7} & \sin \frac{10 \pi}{7} & \cos \frac{20 \pi}{7} & \sin \frac{20 \pi}{7} & \cos \frac{30 \pi}{7} & \sin \frac{30 \pi}{7} & \frac{1}{\sqrt{2}} \\
\cos \frac{12 \pi}{7} & \sin \frac{12 \pi}{7} & \cos \frac{24 \pi}{7} & \sin \frac{24 \pi}{7} & \cos \frac{36 \pi}{7} \sin \frac{36 \pi}{7} & \frac{1}{\sqrt{2}}
\end{array}\right]}
\end{aligned}
$$

Contrary to $\operatorname{mat}\left(\Re_{c}, A B C\right)$, which is diagonal, $\operatorname{mat}\left(\mathfrak{R}_{c}, \alpha \beta\right)$ is a full matrix whose elements are linear combinations of connexion resistances $R_{c A}$ to $R_{c G}$. Then, the opening of phases has an impact over each fictitious machine.

The expression of the connexion matrix in $(d q)$ reference frames is given by (6) with $\operatorname{Rot}(\theta)$ expressed by (7).

$$
\begin{aligned}
& \operatorname{mat}\left(\Re_{c}, d q\right)=[\operatorname{Rot}(-\theta)] \operatorname{mat}\left(\Re_{c}, \alpha \beta\right)[\operatorname{Rot}(\theta)] \\
& \operatorname{Rot}(\theta)=\left[\begin{array}{ccccccc}
\cos \theta & -\sin \theta & 0 & 0 & 0 & 0 & 0 \\
\sin \theta & \cos \theta & 0 & 0 & 0 & 0 & 0 \\
0 & 0 & 1 & 0 & 0 & 0 & 0 \\
0 & 0 & 0 & 1 & 0 & 0 & 0 \\
0 & 0 & 0 & 0 & \cos 3 \theta & -\sin 3 \theta & 0 \\
0 & 0 & 0 & 0 & \sin 3 \theta & \cos 3 \theta & 0 \\
0 & 0 & 0 & 0 & 0 & 0 & 1
\end{array}\right]
\end{aligned}
$$

$\operatorname{mat}\left(\Re_{c}, d q\right)$ is a full matrix and its elements are linear combinations of connexion resistances $R_{c A}$ to $R_{c G}$ and trigonometric functions of $\theta, 2 \theta, 3 \theta, 4 \theta$ and $6 \theta$. It can be then concluded that in open-circuited phase mode, $d q$ voltages are disturbed by speed-dependent harmonic components.

\section{Auto-AdAPTATION OF THE TORQUe CONTROL IN OPEN- Circuited Phase Mode}

\section{A. Adaptation of the number of degrees of freedom of the current control}

The machine being star-coupled, current vector $\vec{i}$ is a 6dimensionnal vector $(7-1=6)$. When some phases are opencircuited, the corresponding currents are physically set to zero. Consequently, the dimension of the 6-dimensionnal current vector is reduced.
A first solution consists in recalculating new current references in order to adapt the dimension of the current reference vector to the number of degrees of freedom of the drive. The new references are chosen in a way that torque is constant and Joule losses are minimized.

Another solution consists in finding new orthogonal subspaces within the machine can be easily controlled.

In this paper, we propose to keep the current control used in normal mode and to adapt its number of degrees of freedom to the number of degrees of freedom of the drive. Since the current control is made in $(d q)$ rotating reference frames, if $m$ phases are open-circuited, $m$ currents in $(d q)$ frames are no longer controlled, i.e. some fictitious machines are no longer controlled.

\section{B. Choice of the fictitious machines not controlled in case of open-circuited phases}

If $m$ phases are open-circuited, only (6-m) $d q$ currents can be controlled. The expression of the $m d q$ currents that are not controlled are imposed by the (6- $m$ ) controlled currents in accordance with physical constraint of nullity of $m$ real currents. Their amplitudes are not equal to zero and, by combination with non-zero EMF, a pulsating torque can appear.

The seven-phase machine, which has been specially designed for fault-operation, has essentially EMF composed of harmonics one and three. Since it has been demonstrated that each fictitious machine is associated with a set of EMF harmonics [12], for the considered machine, only machines $M I$ and $M 3$ are able to produce torque. Whatever currents in $M 2$ machine, they generate only losses.

The chosen strategy is then the following:

- In normal mode, the six $d q$ currents are controlled, i.e. the three fictitious machines. Currents of machine $M 2$, which does not possess EMF, are imposed to zero in order to reduce Joule losses.

- If two phases are open-circuited, currents of machine M2 are no longer controlled.

- If one phase is open-circuited, one another phase is open. Indeed, when only one phase is open, controlling only one current of a fictitious machine leads to disturbances with a large spectrum. The other phase to be opened is chosen in order to balance the temperature on the machine.

The interest of the chosen strategy is essentially that it is simple and gives good results under design constraints for the machine.

\section{Current controller requirements to reject speed-dependent harmonic voltage disturbances in fault-mode}

In normal mode and steady state, current references are constant and voltage disturbances are null. PI controllers are then sufficient. 
In fault mode, even if current references are kept constant, speed-dependent harmonic voltage disturbances appear due to the resistance connection matrix whose elements are variable.

In order to evaluate the current controller requirements in terms of disturbance rejection, the following steps have to be followed.

The first step consists in calculating the $d q$ components of the currents imposed in machine $M 2$. These current components are found with solving the 7 unknowns / 7 equations system presented in (8), where:

- $\quad i_{M 2 d}, i_{M 2 q}$ are the unknowns, to be found

- $i_{M 1 d}, i_{M 1 q}, i_{M 3 d}, i_{M 3 q}$ are kept constant to maintain a constant torque

- $\quad i_{M h}=0$ due to the star-coupling

- two phase currents are set to zero due to the two opencircuited phases

$$
\left(\begin{array}{c}
i_{M 1 d} \\
i_{M 1 q} \\
i_{M 2 d} \\
i_{M 2 q} \\
i_{M 3 d} \\
i_{M 3 q} \\
i_{M h}
\end{array}\right)=[\operatorname{Rot}(-\theta)]\left[C_{7}\right]^{-1}\left(\begin{array}{c}
i_{A} \\
i_{B} \\
i_{C} \\
i_{D} \\
i_{E} \\
i_{F} \\
i_{G}
\end{array}\right)
$$

The second step consists in evaluating the voltage disturbances $\vec{v}_{d i s}=\Re_{c}(\vec{i})$ (see (1)). This evaluation is made by solving (9).

$$
\left(\begin{array}{c}
v_{d i s_{-} l d} \\
v_{d i s_{-} l q} \\
v_{d i s_{-} 2 d} \\
v_{d i s_{-} 2 q} \\
v_{d i s_{-} 3 d} \\
v_{d i s_{3} 3 q} \\
v_{d i s_{-} h}
\end{array}\right)=\operatorname{mat}\left(\mathfrak{R}_{c}, d q\right)\left(\begin{array}{c}
i_{M I d} \\
i_{M I q} \\
i_{M 2 d} \\
i_{M 2 q} \\
i_{M 3 d} \\
i_{M 3 q} \\
i_{M h}
\end{array}\right)
$$

The last step consists in designing the current controllers, which have to be able to track a constant current reference and to reject voltage disturbances $v_{\text {dis }}$. A classical PI controller is used to track the constant reference. Since voltage disturbances are composed of harmonics whose frequencies are multiple of the mechanical speed, beyond a certain speed PI controllers can be not sufficient [13] and auto-adaptive resonant controllers have to be added [14] [15]. These controllers have an infinite gain at a given frequency and are then able to reject harmonic perturbations. Equation (10) gives the transfer function of current controllers $C(s)$, which are able to track constant reference and reject several speed dependent harmonic perturbations. $\Omega$ is the mechanical speed estimated from the position encoder, $p$ the number of pole pairs and $p h \Omega$ the frequency of the disturbance to be rejected ( $h$ positive integer).

$$
\begin{aligned}
& C(s)=C_{P I}(s)+\sum_{h} R_{d q_{-} h}(s) \\
& C_{P I}(s)=K_{p} \frac{1+\tau s}{\tau s} \\
& R_{d q_{-} h}(s)=\frac{a_{2_{-} h} s^{2}+a_{l_{-} h} s+a_{0_{-} h}}{s^{2}+(h p \Omega)^{2}}
\end{aligned}
$$

The parameter tuning of such current controllers are made using pole placement technique according to expected performances

\section{EXPERIMENTAL VALIDATION OF THE AUTO-ADAPTIVE CURRENT CONTROL}

\section{A. Presentation of the experimental setup}

The drive is supplied by a seven-leg voltage source inverter controlled with Pulse Width Modulation at a frequency of $20 \mathrm{kHz}$. The DC bus voltage is set to $400 \mathrm{~V}$. Fig. 3 shows a snapshot of the experimental setup.

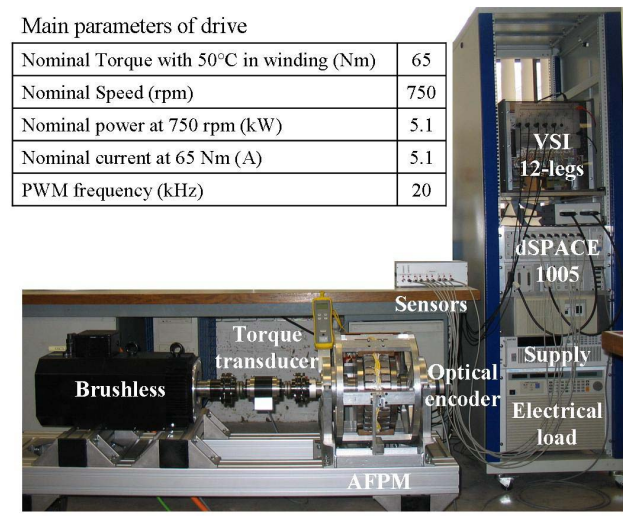

Fig. 3. Experimental setup

\section{B. Experimental results}

The mechanical load is composed of a DC brushless machine whose speed is controlled at $30 \mathrm{rad} / \mathrm{s}$.

\section{Normal Mode (FM)}

Current references are set to the following values:

$i_{M 1 d}=0, i_{M 1 q}=-3 A, i_{M 2 d}=0, i_{M 2 q}=0, i_{M 3 d}=0, i_{M 3 q}=-1 \mathrm{~A}$.

As shown in Fig.4 and Fig.9, $d q$ currents are almost constant and the torque, produced by machines $M 1$ and $M 3$ is almost constant (see trace $c_{N M}$ in Fig.8). Phase currents are balanced as shown in Fig.5.

Fault Mode (FM1) keeping the same current control as in normal mode

Fig.6 shows $d q$ currents in machines $M 1$ and $M 3$ when phases $C$ and $D$ are open-circuited with keeping the same current references and current control as in normal mode. As expected, $d q$ currents are not constant and the electromagnetic torque $c_{F M 1}$ possesses high ripples (See Fig.8). 
Fault Mode (FM2) using the proposed auto-adaptive faulttolerant current control

$d q$ current references in machines $M 1$ and $M 3$ are kept the same as in normal mode and $d q$ currents of machine $M 2$ are no longer controlled. As a consequence and according to (8), currents in machine $M 2$ are not null and are mainly composed of harmonics 1 and 3 (see Fig.7). None zero currents in machine $M 2$ have no influence over the torque quality since the machine has be designed in order not to have fifth harmonic of EMFs (which leads to null EMFs in $M 2$ machine).

According to (9), in order to have constant $d q$ currents in machines $M 1$ and $M 3$ corresponding $d q$ voltages must possess harmonics 2, 4 and 6 in order to compensate for the harmonic voltage disturbances $v_{\text {dis }}$ (see Fig.9). The use of auto-adaptive resonant current controllers makes possible the rejection of such harmonic voltage disturbances. Fig.10 shows the transfer function of such controllers for two different mechanical speeds. Estimated from the position encoder, the mechanical speed is used to adapt the resonating frequencies of resonant controllers presented in (10). To limit the complexity of the proposed current controllers, only the two larger harmonic voltages are rejected (harmonics 2 and 6 for $M 1$ and 2 and 4 for M3). Finally, to keep the same pole placement, coefficients $a$ of current controllers $R_{d q} h$ are updated at each computation time.

Since $d q$ currents in machines $M 1$ and $M 3$ are almost kept constant (see Fig.4), as shown in Fig.8 the torque has few ripples (see trace $c_{F M 2}$ ).

Finally, it has to be noticed that phase currents in fault mode have balanced peak values.

\section{CONCLUSION}

This paper shows a simple way to control multi-phase machines with open-circuited phases. Under the condition of a machine specifically designed and the adaptation of the number of degrees of freedom of the control scheme, it is possible to keep a constant torque in fault mode with keeping the same multiple $d q$ reference frame control structure as in normal mode. Using connection resistances, a unique model of the drive, viable in normal as in fault mode, is developed. Based on this modelling, an analysis of the speed-dependent harmonic voltage disturbances appearing in fault-mode makes possible to define the necessary performances of auto-adaptive resonant current controllers. Finally, experimental results show the simplicity and the effectiveness of the proposed method to control the torque in fault-mode.

\section{REFERENCES}

[1] E.Levi, "Multiphase Electric Machines for Variable Speed", IEEE Trans. on Industrial Electronics, vol. 55, no. 5, May 2008

[2] X. Kestelyn, E. Semail, Y.Crévits, "Generation of On-line Optimal Current References for Multi-phase Permanent Magnet Machines with Open-circuited Phases" IEEE International Electric Machines \& Drives Conference, vol.2, pp.1131-1135, May 2009.

[3] R. Fu, T.A. Lipo, "Disturbance-free operation of a multiphase current-regulated motor drive with an opened phase," IEEE Trans. on Industry Applications, vol.30, no.5, pp.1267-1274, Sep/Oct 1994
[4] J. Wang, K. Atallah, D. Howe, "Optimal torque control of faulttolerant permanent magnet brushless machines", IEEE Trans. on Magnetics, vol. 39, issue: 5, pp. 2962-2964, Sept. 2003.

[5] N. Bianchi, S. Bolognani, M.D. Pre, "Strategies for the FaultTolerant Current Control of a Five-Phase Permanent-Magnet Motor", IEEE Trans. on Industry Applications, vol.43, no.4, pp.960970, July-aug. 2007

[6] S. Dwari, L. Parsa, "An Optimal Control Technique for Multiphase PM Machines Under Open-Circuit Faults," IEEE Trans. on Industrial Electronics, vol.55, no.5, pp.1988-1995, May 2008.

[7] F. Locment, E. Semail, X. Kestelyn, "Vectorial Approach-Based Control of a Seven-Phase Axial Flux Machine Designed for Fault Operation,", IEEE Trans. on Industrial Electronics, vol.55, no.10, pp.3682-3691, Oct. 2008

[8] H. M. Ryu, J. H. Kim and S. K. Sul, "Synchronous-Frame Current Control of Multiphase Synchronous Motor Under Asymmetric Fault Condition due to Open Phases", IEEE Trans. on Industry Applications, vol. 42, n 4 , July/August 2006, pp.1062-1070.

[9] E. Semail, X. Kestelyn, F. Locment, "Fault Tolerant Multiphase Electrical Drives: The Impact of Design", EPJ AP (European Physical Journal-Applied Physics), Vol 43, n², August 2008

[10] X. Kestelyn, F. Locment, Y. Crevits, E. Semail, "Easy-to-Implement Integral Numerical Simulation of Multi-phase Drives under Fault Supply Condition," Proc. of IEMDC '07, IEEE International Electric Machines \& Drives Conference, vol.2, pp.1131-1135, May 2007.

[11] H. M. Ryu, J. W. Kim and S. K. Sul, "Synchronous Frame Curren Control of Multi-Phase Synchronous Motor, Part I. Modeling and Current Control Based on Multiple d-q Spaces Concept Under Balanced Condition", Proc. of IEEE-IAS'04, vol. 1, pp. 56-63, Seattle (USA), Oct. 2004.

[12] E. Semail, X. Kestelyn and A. Bouscayrol, "Right Harmonic Spectrum for the back-electromotive force of a n-phase synchronous motor", Proc. of IEEE-IAS'04, Seattle (USA), Oct. 2004, Vol. 1, pp.71-78.

[13] X.Kestelyn, Y.Crevits, E.Semail,'Fault Tolerant Control of a Sevenphase Drive by Degrees of Freedom Adaptation", ICIT2010,3-2010

[14] L.R Limongi, R.Bojoi, G.Griva and A.Tenconi, "Digital Currentcontrol Scheme", IEEE Industrial Electronics Magazine, March 2009.

[15] Y.Crevits, X.Kestelyn, E.Semail, "Investigation on Vector control of three-phase synchronous machines under supply fault conditions", SPEEDAM 2006, 5-2006

[16] Y.Crevits, Xavier Kestelyn, Betty Lemaire-Semail, "Analysis and Implementation of a 2-Degree Of Freedom Control for a ThreePhase Induction Machine", EPE2007, 9-2007
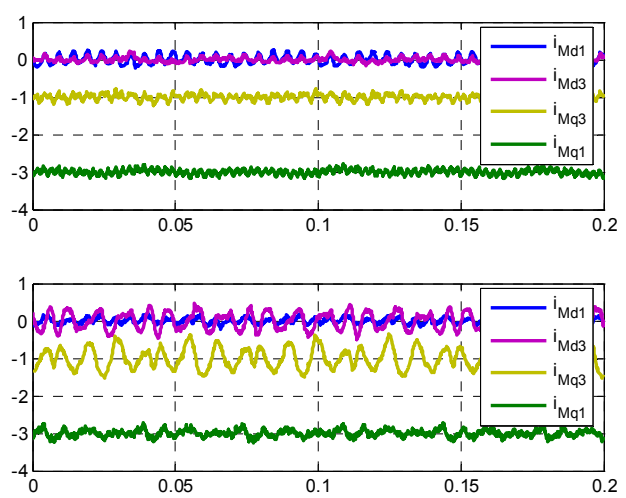

Fig. 4. dq currents (Machines M1 and M3) in normal mode and with two open-circuited phases when the proposed strategy is applied (FM2 mode)

(Experimental Results) 

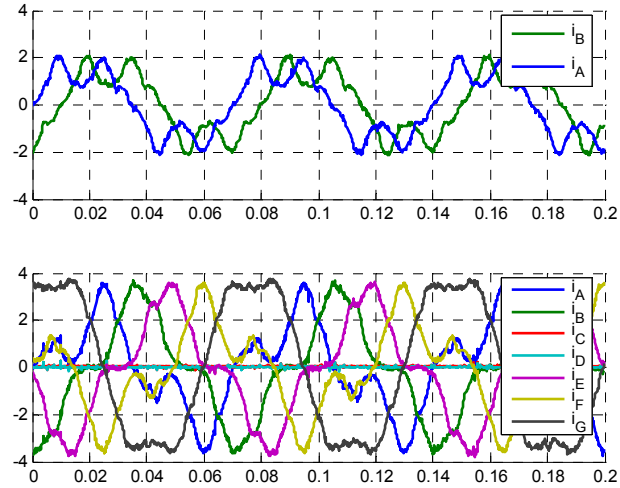

Fig. 5. Phase currents in normal mode and with two open-circuited phases when the proposed strategy is applied (FM2 mode) (Experimental Results)

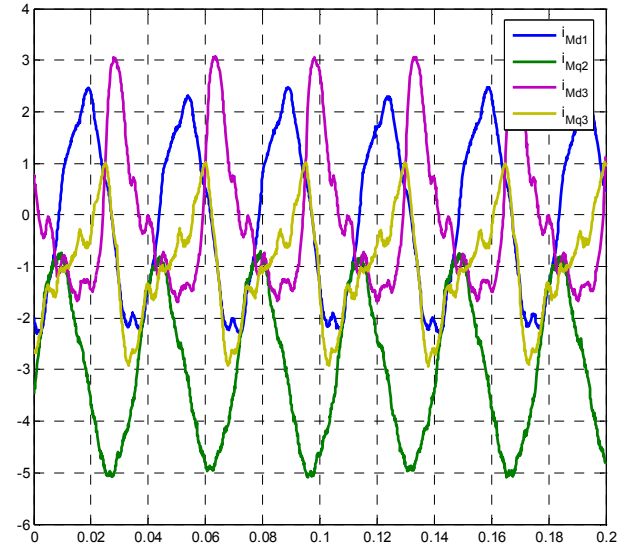

Fig. 6. dq currents in fault mode (FM1) keeping the same current control as in normal mode- Machines M1 and M3 (Experimental Results)

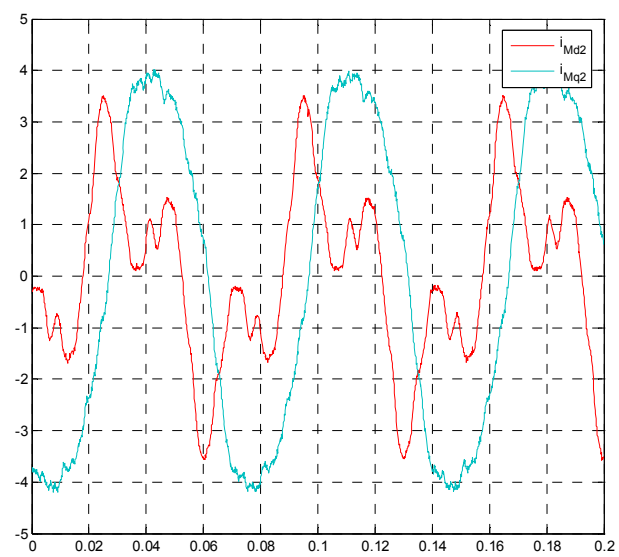

Fig. 7. dq currents in fault mode (FM2) using the proposed autoadaptive current control-Machine M2 (Experimental Results)

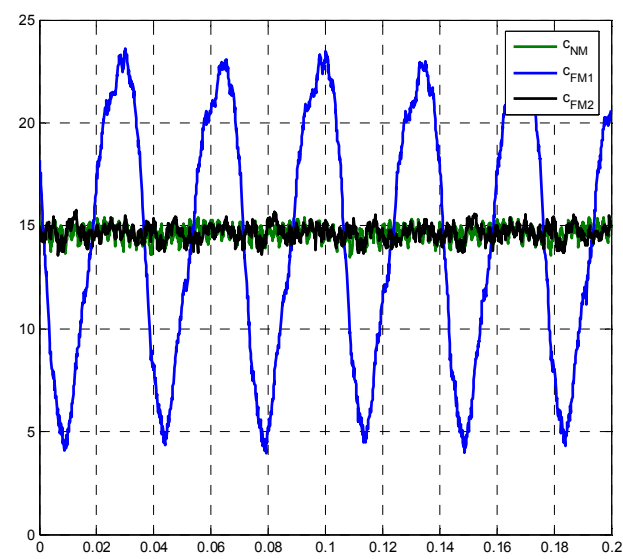

Fig. 8. Torques in normal and $\mathrm{f}$ $\mu$ (Experimental Results)

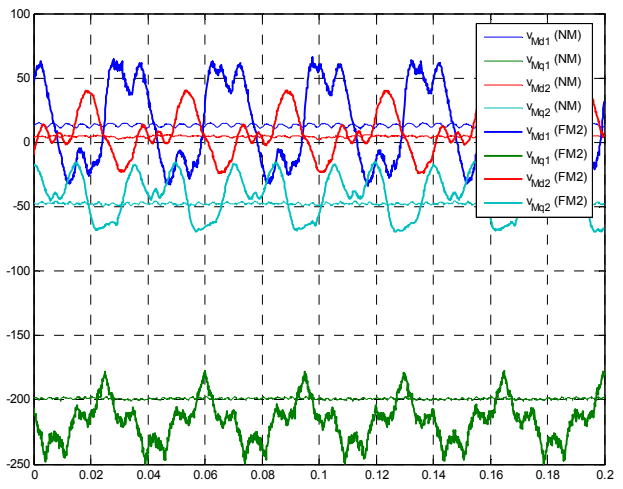

Fig. 9. dq reference voltages in normal mode (NM) and in fault mode using the proposed auto-adaptive current control (FM2) (Experimental Results)

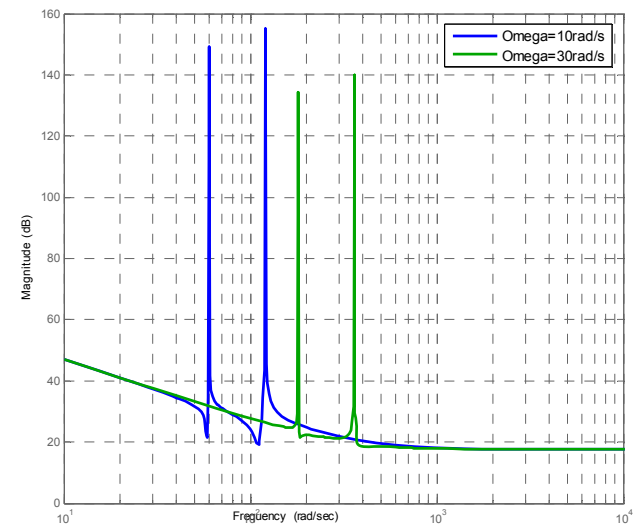

Fig. 10. Transfer function of the proposed auto-adaptive current controllers at two different mechanical speeds 